\title{
Chapter Thirty-Two \\ Non-Compliance Mechanisms: Lessons Learned and the Way Forward
}

\author{
Attila Tanzi and Cesare Pitea*
}

\section{INTRODUCTORY REMARKS}

In a short period of time non-compliance mechanisms have become a sort of a "must" within the institutional regimes established by multilateral environmental agreements (MEAs). This testifies to the fairly general consensus that has developed among negotiators on the need to establish similar procedures, with special regard to the particular standard-type studied in this book: namely, one in which specific cases of non-compliance are dealt with by a specialised standing treaty body. The appropriateness of such mechanisms is rarely questioned, while controversy only arises as to the way they should be designed, with special regard to a few discrete points. This has led to a number of variations on the theme. As highlighted throughout the present book, the main differences concern the composition of the relevant body, the subjects entitled to initiate the procedure and the relationship between the compliance body and the $\mathrm{COP} / \mathrm{MOP}$, with specific regard to their respective powers on the matter in hand.

This simple observation, however, does not preclude the possibility of making considerations of a more general nature. Firstly, there is widespread agreement on the fact that these mechanisms are to be non-judicial, non-confrontational and consultative. ${ }^{1}$ This means that States generally refuse to conceive these mechanisms as instruments for a third-party binding determination of whether the relevant obligations have been complied with or not. Secondly, there is a common perception that these mechanisms should primarily aim at facilitating compliance rather than stigmatising the concerned party. Thirdly, their effectiveness relies heavily on cooperation by the party experiencing difficulties in complying, in that it should itself bring the issue

\footnotetext{
* This chapter is the result of common reflections by the two authors - Paras. 1 and 2 were written by Attila Tanzi and para. 3 by Cesare Pitea.

${ }^{1}$ With the possible exception of the mechanism established under the Kyoto Protocol, whose Art. 18 requires the Parties to set up "appropriate and effective procedures and mechanisms to determine and to address cases of non-compliance with the provisions of this Protocol." Decision 27/CMP.1 indicates that the "[...] procedures and mechanisms are to facilitate, promote and enforce compliance [...]", see S. Urbinati, "Procedures and Mechanisms Relating to Compliance under the 1997 Kyoto Protocol to the 1992 United Nations Framework Convention on Climate Change", supra 63-94, at 67-68.
}

T. Treves et al., eds., Non-Compliance Procedures and Mechanisms and the Effectiveness of International Environmental Agreements

(C) 2009, T.M.C. AsSER PRESS, The Hague, The Netherlands, and the Authors 
before the relevant body or, at least, engage constructively in a process leading to the pinpointing of the reasons for and origins of non-compliance, as well as of the tools (and possibly resources) to remedy to the situation.

Although academia has never neglected the importance non-compliance mechanisms may have, scholars have mainly focused, through some seminal studies, on the theoretical basis for establishing such mechanisms and on how they relate with wellknown concepts of public international law. ${ }^{2}$ Another branch of scholarship has dwelled on the issue of their legal nature. ${ }^{3}$ However, due to their timing, these reflections have been highly theoretical in most cases, based on the observation of the mere textual element or, at most, of the narrow practice existing at the time of their writing. Less attention has been devoted to the more practical issue of how these mechanisms function in practice, in order to provide criteria for assessing their effectiveness and to identify whether this is influenced by certain features.

The research and discussion which have led to the present book have suggested a different approach. Also taking advantage of the latest developments of practice in this field, it is based on the assumption that trying to identify a common legal nature for non-compliance mechanisms simply by looking at their founding instruments is an impossible and far from useful exercise. It appears that, apart from the differences already noted between the various mechanisms, the overall phenomenon is still undergoing an evolutionary phase. COP/MOPs keep these mechanisms very much under observation and the flexibility of the instrument used to establish them - usually a COP/MOP decision - easily allows their amendment and modification. More importantly, given their innovative and to some extent unclear nature, in order to make a legal assessment of the phenomenon in point, what actually happens in practice is of crucial importance. Namely, it appears that the legal nature of each of these mechanisms is to a large extent being shaped by the way the women and men taking part in their functioning conceive their mandate.

However, a mere recognition of practice cannot be conclusive. Alongside a comparative analysis, a selective approach is suggested with a view to identifying formulae that best conform to the rationale underlying the very establishment of such mechanisms. Against such a rationale emerging from each given case, some minimum features of a general character for testing the effectiveness of a non-compliance mechanism will be suggested. This may allow for a fresh look at the long-debated issue of the legal nature of the mechanisms under review without forcing them into

\footnotetext{
${ }^{2}$ Especially relevant are the studies by M. Koskenniemi, "Breach of Treaty or Non-Compliance? Reflections on the Enforcement of the Montreal Protocol", YB Int'l Envt'l L., 3 (1992) 123-161 and by M. Fitzmaurice and C. Redgwell, "Environmental Non-Compliance Procedures and International Law, Netherlands YB Int'l L., XXXI (2000) 35-65.

3 See, for example, J. Voünov Kohler, Le mécanisme de contrôle du respect du Protocole de Kyoto sur les changements climatiques: entre diplomatie et droit (Zurich: Schulthess, 2006), especially at 110-124. See also C. Pitea, "The Non-Compliance Procedure of the Aarhus Convention: Between Environmental and Human Rights Control Mechanisms", Italian YB Int'l L., 16 (2006) 85-116, at 104-105; L. Boisson de Chazournes and M.M. Mbengue, "Nature. A propos du caractère juridictionnel de la procedure de nonrespect du Protocole de Kyoto", in S. Maljean-Dubois (ed.), Changements climatiques les enjeux du contrôle international (Paris: La Documentation Française, 2007) 73-109.
} 
the overemphasized dichotomy between the diplomatic and judicial means of dispute mechanisms. ${ }^{4}$

Needless to say, this approach is far from being neutral in terms of value judgment and the conclusions reached in the present chapter, inasmuch as they are the sole responsibility of its authors, owe much to the collective discussion which took place at the Milan Conference as reflected throughout the present book. ${ }^{5}$

\section{The Purpose of Non-Compliance Mechanisms and the Factors ENHANCING THEIR EFFECTIVE FUNCTIONING}

\subsection{A Means to Enhance the Effectiveness of International Environmental Law}

The establishment of non-compliance mechanisms is firmly rooted in the need to foster the effectiveness of MEAs, upon consideration of the fact that traditional means for the enforcement of international law, including dispute settlement, have not proved fully appropriate in this particular field. ${ }^{6}$

Other reasons may induce States individually to propose and accept non-compliance mechanisms. This may include the need for Governments to appear as supporters of environmental protection before domestic and international public opinion or the prospects that such procedures may result in financial or technical support for the implementation of the relevant treaty obligations. ${ }^{7}$ Pessimists have made the case that the establishment of weak compliance mechanisms is aimed at providing a (costly) shield of good intentions behind which States may hide their unwillingness to have their obligations seriously scrutinized. ${ }^{8}$ Be that as it may, the general aim of the procedures under consideration is that of enhancing the effectiveness of their international obligations in the field, and practice has not provided evidence to the contrary.

Thus, the present chapter moves from the simple consideration that non-compliance mechanisms aim at ensuring and improving the compliance rate by the Parties to a given MEA on a non-selective and objective basis. For it appears that their

${ }^{4}$ On complementarity between judicial and diplomatic means of dispute settlement, see A. Tanzi, Introduzione al diritto internazionale contemporaneo (Padua: Cedam, 2006, $2^{\text {nd }}$ edn.), at 345-346.

5 An account of the Conference is given by A. Broggiato, "Non-Compliance Mechanisms and International Environmental Law", Env. Pol'y \& L. 38 (2008) 70-73.

${ }^{6}$ Koskenniemi, supra n. 2, at 125-128; R. Wolfrum, "Means of Ensuring Compliance with and Enforcement of International Environmental Law", $R d C$, 272 (1999) 9-154, at 96-100; M. Ehrmann, "Procedures of Compliance Control in International Environmental Treaties”, Colo. J. Envt'l L. \& Pol'y, 13 (2002) 377-443, at 435-436. For a more general analysis and further references, C. Romano, "International Dispute Settlement", in D. Bodansky, J. Brunée and E. Hey (eds.), Oxford Handbook of International Environmental Law (Oxford: Oxford University Press, 2007), 1037-1056.

7 See F. Romanin Jacur, "Controlling and Assisting Compliance: Financial Aspects", supra 419-437.

${ }^{8}$ A softer version of this position is taken by G. Ulfstein, T. Marahun, and A. Zimmermann, "Introduction", in G. Ulfstein, T. Marauhn, and A. Zimmermann (eds.), Making Treaties Work. Human Rights, Environment and Arms Control (Cambridge: Cambridge University Press, 2007) 3-12, at 3, who claim that a possible reason for the establishment of non-compliance procedures is that they allow more control by States over the process and its outcome than adjudication. 
legitimacy and effectiveness depend on their capacity to serve the common interest of the Parties as it is reflected in the treaty obligations they have undertaken.

To this end, compliance bodies must be such as to be able to consider the widest possible number of cases, regardless of the State or States concerned and of the political aspects involved. Also, if the rate of activity of a non-compliance mechanism is low, due to the lack of action by authorised subjects or to the frequent dismission of cases on procedural grounds by the compliance body, the usefulness of its very raison d'être comes into question. A further element enhancing effectiveness is the ability of this mechanism to engage the States concerned in the process of compliance review, since cooperation by them is co-essential for their functioning. However, the desire to engage States should not sacrifice the integrity of legal rules by legitimising deviations from the relevant obligations, otherwise the overall purpose of the mechanism would be frustrated altogether.

From these assumptions a number of preliminary elements have emerged as a key to assessing the effectiveness of compliance mechanisms and they are dealt with in the following subsections.

\subsection{Mandate. Between the Political and Legal Dimensions}

A major issue is how the mandate of a compliance body should be interpreted by the latter. The question may also depend on the relationship between compliance bodies and COP/MOPs. Some compliance bodies may regard themselves as political forums in which compliance issues are negotiated "on behalf" of the COP/MOP. Were this to be the case the workings of a compliance body would be tantamount to a preparatory stage of the decision-making process of the COP/MOP. This approach raises serious doubts as to the possibility for the compliance body to be up to an objective minimum standard of effectiveness. Indeed, according to this rather extreme position compliance mechanisms would be conceived as an especially "proceduralised" form of multilateral negotiation on the content and implementation of MEAs obligations, in which any evaluation would be of a political nature and there would be no place for legal assessment. ${ }^{9}$ It is difficult to subscribe to this approach on several counts, two of which deserve to be singled out. First, from a purely legal perspective, this would institutionalise the idea that treaty obligations may be subject to continuous renegotiation, through the political determinations of the COP/MOP or of a subsidiary body having the same political nature. According to this reasoning, treaty law would be turned into soft law. ${ }^{10}$ Although MEAs often provide for simplified and unconventional law-making processes, they never go so far as to question so radically

9 This is sometimes expressed by those that emphasize the "diplomatic" nature of compliance procedures, see J. Klabbers, "Compliance Procedures", in D. Bodansky, J. Brunée and E. Hey (eds.), Oxford Handbook of International Environmental Law (Oxford: Oxford University Press, 2007) 995-1009, at 998.

${ }^{10}$ Jan Klabbers has gone further by indicating compliance procedures, and the terminology associated with them, as one of the elements of a more general move towards "turning international law into a commodity, to be used when desired, and to be disused when deemd unproductive", see J. Klabbers, "The Commodification of International Law", in H. Ruiz Fabri, E. Jouannet and V. Tomkiewicz (eds.), Select Proceedings of the European Society of International Law, Volume I, 2006 (Oxford and Portland: Hart, 2008) 341-358, at 343 and 349-350. 
the supremacy of treaty law over derived regulatory instruments. ${ }^{11}$ Second, from a broader policy perspective this approach would expose compliance to the differences in power among various parties. This would frustrate one of the basic reasons for establishing such mechanisms, which is precisely that of pursuing uniform implementation and safeguarding for all Parties the integrity of the common interest protected by the provisions of the treaty.

In order to avoid this risk, it is for each compliance body to interpret its mandate without losing sight of the core task of assessing, objectively and in accordance with legal criteria, whether the Parties' conduct conforms to the obligations they have freely assumed. ${ }^{12}$ This, of course, should not exclude flexibility and the balancing of interest considerations in the compliance-related decision-making process.

Once an assessment of compliance or non-compliance has been made objectively under international law, the compliance process leaves plenty of room for flexibility and political considerations. It does not require the automatic stigmatisation of noncompliance, nor the adoption of any negative consequence thereof for the non-complying State that accepts to be engaged in the process. Rather, the legal assessment is functional to the identification of the origins and the possible solutions of compliance problems through technical advice and, possibly, assistance. There is no denying that a fair degree of political discretion is the key feature of compliance review processes and that its exercise on a case-by-case basis may enhance their effectiveness. Indeed, States' reluctance to submit the review of their international commitments in the environmental field to traditional third party determination is - with special regard to judicial settlement - one of main reasons for the proliferation of the sui generis compliance procedures. Therefore, a non-confrontational attitude remains key to obtain the appropriate cooperation by States. However, the case is made that, from a general consideration of the mandates of the compliance bodies under review, such concerns may well be addressed without endangering the integrity of the legal rules against which compliance has to be assessed.

\subsection{Composition and the Issue of Independence}

The framing of compliance procedures as purely political processes is normally associated with compliance bodies composed of Parties and, often, with those operating with a high degree of confidentiality and with a strict control of triggering by States. As Alessandro Fodella has observed, ${ }^{13}$ there is a close relationship between the composition of a compliance body and the way in which it interprets and discharges its mandate. A body composed of State representatives is normally more inclined to negotiation and compromise than one composed of independent experts.

${ }^{11}$ See M. Fitzmaurice, "Non-Compliance Procedures and the Law of Treaties", supra 453-481, at $455-467$.

12 As already noted elsewhere, the definition of non-compliance used by the Compliance Committee of the Aarhus Convention refutes the idea that the NCP is a political process leading to a political assessment and apart from the terminology used, makes it difficult any distinction with the notion of breach under the law of State responsibility, see also Pitea, supra n. 3, at 104-105.

13 A. Fodella, "Structural and Institutional Aspects of Non-Compliance Mechanisms", supra 355-372, at 360 
Furthermore, this kind of composition hardly ensures continuity in membership, since the same government may designate a different representative for each meeting, and may result in argumentative inconsistency. In line with the observations made in the previous paragraph, compliance bodies appear to be able to best discharge their mandate objectively when composed of independent experts or, at least, of government representatives bound to serve continuously and objectively.

Nevertheless, practice shows that this assumption may not always prove to be true. For instance, Jerzy Jendrośka has observed that, so far, the political composition of the Espoo Convention Implementation Committee did not have an adverse effect on its objectivity. ${ }^{14}$ In certain cases, as underlined by Tullio Treves, a body composed of States may even authoritatively take politically bold stands that a body of experts could not take. ${ }^{15}$ Conversely, the case may be that even when the full independence of members is provided for by the relevant constitutive instrument, a compliance review process may remain highly politicised, as is the case with the non-compliance mechanism under the Kyoto Protocol, as one may infer from the report by René Lefeber. ${ }^{16}$

Another point concerning the composition of compliance bodies which may significantly bear on their functioning concerns the need for a balance between the technical experts in the field covered by the relevant convention and legal experts who are particularly knowledgeable in international law. The problem arises irrespective of whether the body concerned is composed of independent individuals or government representatives. It is self-evident that MEAs, as sources of international law, are to be interpreted in accordance with international law and in the context of general international law. This has recently emerged more fully during consideration of the Bystroe Project case by the Espoo Convention Implementation Committee in relation to the existence of an obligation for the Party concerned to suspend the related works, pending the assessment by an Inquiry Commission about the existence of a significant transboundary adverse effect ${ }^{17}$ and, consequently, the applicability of the Espoo Convention. As underlined by Jerzy Jendrośka in his chapter, the Committee did not find such an obligation in the Convention itself, but referred to general international law as its source. The decision establishing the Implementation Committee of the Espoo Convention does not require States to designate representatives with legal skills for the Committee's meetings and the presence of two members with a legal background may be considered to have occurred by accident. One may wonder whether the decision of the Committee on the case in point would have been the same otherwise.

14 J. Jendrośka, "Practice and Relevant Cases that Emerged in the Context of the Espoo Convention Implementation Committee", supra 319-335, at 326.

15 See T. Treves, "Introduction", supra 1-8, at 5, commenting the decision of the Montreal Protocol Implementation Committee to qualify the request for a grace period submitted by the Russian Federation as a "submission" to the non-compliance procedure.

${ }^{16}$ R. Lefeber, "The Practice of the Compliance Committee under the Kyoto Protocol to the United Nations Framework Convention on Climate Change (2006-2007)", supra 303-317.

${ }_{17}$ On the role of the inquiry commission within the Espoo Convention and on the Bystroe Project case, see E. Fasoli, "Procedures and Mechanisms for Review of Compliance under the 1991 Espoo Convention on Environmental Impact Assessment in a Transboundary Context and its 2003 Protocol on Strategic Environmental Assessment”, supra 181-203, at 198-199, and Jendrośka, supra n. 14, at 331-332. 


\subsection{The Relationship between Compliance Bodies and COP/MOPs}

Closely connected with the issue of the independence of compliance bodies is their relationship with COP/MOPs. Apart from the formal question whether compliance bodies are to be classified as "subsidiary bodies" of the COP/MOP, or otherwise, ${ }^{18}$ what appears to be of substantive relevance is what the actual division of powers between the two bodies is and the relationship between them. As Alessandro Fodella has observed, a compliance body composed of States representatives "may end up being nothing more than a way of managing more efficiently the political compliance review competence of the governing body of the treaty in a decentralized manner." 19 These words run counter to the assumption made above that the mandate of an effective compliance body should not be interpreted in such a way as to give it a strictly political connotation in order for it to adhere to the basic rationale of the compliance control function. Accordingly, the basic autonomy of compliance bodies from the political governing body of the relevant convention is a prerequisite for their minimum effectiveness.

As a matter of fact, this need appears to be met by practice: indeed, the governing bodies of MEAs have so far avoided interfering with the merits of a case before compliance bodies, consistently endorsing their findings and recommendations. For the purposes of optimal effectiveness, a compliance body should be able to assess without political interference whether a given situation amounts to non-compliance and indicate what type of action it deems appropriate. It should also be vested with the power to formulate its recommendations - at least on facilitative measures and/or on a provisional basis - directly to the Party concerned, in order to avoid delays due to the long intervals between COP/MOPs.

At the same time, the above consideration is not meant to downplay in any way the decision-making role of COP/MOPs. Indeed, leaving the formal decision-making on compliance issues with the political governing body may have several advantages. From a political point of view, it generates a feeling of ownership of the decision by the Parties as a whole, thus enhancing its legitimacy. From a strictly legal perspective, any decision of a compliance body backed by the COP/MOP through its adoption by consensus, especially when the provision at stake has been consistently interpreted in a certain way in different cases without objections by Parties, may amount to "subsequent practice in the application of the treaty" which, under Article 31.3(b) of the Vienna Convention, shall be taken into account when interpreting a treaty.

${ }^{18}$ See the different points of view expressed, with reference to the Aarhus Convention Compliance Committee by V. Koester, "The Compliance Mechanisms of the Aarhus Convention and the Cartagena Protocol on Biosafety: A Comparative Analysis of the Negotiation Histories and their Outcomes", supra 277-302, at 298, and C. Pitea, "Procedures and Mechanisms for Review of Compliance under the 1998 Aarhus Convention on Access to Information, Public Participation and Access to Justice in Environmental Matters", supra 221-249, at 227.

${ }_{19}$ Fodella, supra n. 13, at 360. 


\subsection{Transparency and the Role of non-State Actors}

As to the issue of transparency in compliance mechanisms, a general consensus has emerged in the opinions of the scholars and practitioners involved in the preparation of this book to the effect that it should be set out as a general rule of non-compliance mechanisms. However, this view is not fully reflected in the constituent decisions and actual practice of existing mechanisms. Apart from those established very recently, the view that confidentiality better ensures cooperation by States still prevails. Thus, in most cases, the meetings of compliance bodies take place in closed session when specific cases of non-compliance are considered and compliance related information may be held confidential. This reflects the traditional approach to diplomatic means of settlement, where confidentiality is considered as some kind of due deference to national sovereignty.

Nowadays, this approach seems to a large degree outdated. Following Principle 10 of the Rio Declaration, ${ }^{20}$ transparency emerges as a normative principle of international environmental governance and, as such, it should also apply to compliance review processes. ${ }^{21}$ One may also add that scrutiny of the work of compliance bodies by Parties and by the public may also help to ensure that the procedures in point are carried out on a fair and equitable basis. It appears, therefore, advisable that compliance procedures should adopt transparency (i.e., openness of meetings and publicity of information) as the rule. Confidentiality may be kept in well-defined cases (such those when it is necessary to protect international relations, national defence or public security or the secrecy of commercial and industrial information or to protect intellectual property rights), in the deliberation phase, as well as an incentive for States to make submissions on their own compliance. One could make the case that regulation on the matter applicable to the Aarhus Convention non-compliance procedure ${ }^{22}$ provides an advanced model from which inspiration may be drawn.

The issue of transparency often goes hand in hand with that of the participation of civil society. ${ }^{23}$ While participation by NGOs and the public in the mechanisms under consideration may play an important role in ensuring fairness in the proceedings, only exceptionally are NGOs vested with the power to trigger such mechanisms on

${ }^{20}$ Rio Declaration on Environment and Development, doc. A/CONF.151/26 (Vol. I) (12 August 1992), Annex I. According to Principle 10 of the Declaration, "[e]nvironmental issues are best handled with participation of all concerned citizens, at the relevant level. At the national level, each individual shall have appropriate access to information concerning the environment that is held by public authorities, including information on hazardous materials and activities in their communities, and the opportunity to participate in decision-making processes. States shall facilitate and encourage public awareness and participation by making information widely available. Effective access to judicial and administrative proceedings, including redress and remedy, shall be provided."

${ }^{21}$ On reluctance by States to fully accept NGOs as actors in the field of international environmental law, see A. Tanzi, "Controversial Developments in the Field of Public Participation in the International Environmental Law Process", in P.M. Dupuy and L. Vierucci (eds.), NGOs in International Law. Efficiency in Flexibility (London: EE, 2008) 135-152.

22 See C. Pitea, supra n. 18, at 235.

${ }^{23}$ For a more comprehensive view on the role of NGOs and civil society in compliance mechanisms, see C. Pitea, "The Legal Status of NGOs in Environmental Non-Compliance Procedures: An Assessment of Law and Practice”, in Dupuy and Vierucci, supra n. 21, 181-203. 
individual cases of non-compliance. Such a possibility is generally regarded with hesitation, if not suspicion, by States. Less controversial is the possibility for a committee to use information coming from non-governmental sources, possibly taking advantage of an NGO's expertise, in proceedings already initiated by other subjects. Attempts to limit the role of NGOs as sources of information ${ }^{24}$ are reasons for particular concern to those who fear the undermining of the effectiveness of non-compliance procedures.

Particularly controversial is the question of the possible recognition to NGOs, or to the public, of the power to trigger non-compliance procedures. It is self-evident that allowing non-State actors to bring individual cases to the attention of a compliance body would enhance significantly the effectiveness of the mechanisms in point. It would help in identifying cases of non-compliance, and the causes thereof, through factual information and scientific and legal assessment. Such a contribution would be particularly desirable in view of the fact that NGOs are usually less - if at all - constrained than States by considerations of 'diplomatic appropriateness' in raising often delicate issues of non-compliance with environmental standards and rules. Regardless of the specific kind of civil society participation and notwithstanding the advantages in terms of fairness and effectiveness, this question is met with a fundamental objection by States, namely that it could undermine the non-confrontational and cooperative nature of the mechanism. The practical concern is also felt that, if the procedure may be triggered also by actors other then states, the Committees' agendas could become overloaded, with the consequent increase in the costs of the procedure.

Although progress in enhancing public participation has been made in some UNECE non-compliance procedures, it still generally appears to be difficult and even hardly negotiable to increase the role of NGOs in compliance mechanisms with regard to global treaties. In such a context, the reluctance of some relevant western States adds to the traditional opposition by developing countries. Practice shows that, when NGOs have been recognised a significant role in the procedures under consideration, they have discharged the responsibilities entrusted to them with diligence and efficiently, furthering the effectiveness of the compliance review action. One could say that recognition of a formal status for NGOs seems to enhance their transparency and accountability, at least within the area under consideration.

\section{Beyond Claims of State Responsibility through Inter-State Dispute} Settlement: the Legal Nature of Non-Compliance Mechanisms

The debate around the issue of the legal nature of compliance mechanisms and procedures is often constrained into the classical dichotomy between "diplomatic" and "judicial" procedures for the settlement of international disputes. As already observed, a compliance mechanism characterised by a body with a purely political mandate, composed of States representatives and deciding according to purely political criteria,

${ }^{24}$ See A. Fodella, "Mechanism for Promoting Implementation and Compliance with the 1989 Basel Convention on the Transboundary Movements of Hazardous Wastes and Their Disposal", supra 33-48, at 43 . 
can be classified as a sui generis diplomatic procedure for the settlement, and possibly for the prevention, of disputes.

We have also made the case that this kind of mechanism can hardly be effective and meet the objective of enhancing the effectiveness of treaty obligations within its competence. In most cases, tough, non-compliance procedures deviate from a purely diplomatic model. Therefore, a certain trend may be discerned among scholars in favour of qualifying those mechanisms, or at least some of them, as "quasi-judicial", ${ }^{25}$ thus underlining their proximity with mechanisms that are already known in other branches of public international law. Such a qualification, however, has little or no significance if it is not accompanied by substantive indications. Some authors have engaged in the exercise of measuring the degree of "judiciality" of non-compliance mechanisms by reference to certain criteria or features that belong to judicial bodies. ${ }^{26}$ To that end, reference has been made to independence and impartiality, existence of procedural guarantees for all the subjects involved, competence to ascertain the violation of a legal obligation and the binding force of such an assessment. If these criteria are applied, however, it is evident that almost all of the mechanisms concerned will fail to pass the test, with the possible exception of the mechanisms established under the Kyoto Protocol and the Aarhus Convention (and those modelled after the latter).

This approach, although methodologically rigorous, when applied to the generality of non-compliance procedures fails to grasp their reality and specificity, forcing them into categories of classical inter-State dispute settlement for classification purposes far removed from apparent practical use. Although it is not impossible for some of the non-compliance mechanisms to develop in the medium or long run into classical judicial or quasi-judicial dispute settlement procedures, one can make the case that, generally considered, they are a genus on their own, which can hardly be forced into the traditional categories of dispute settlement. At present, a different approach is suggested.

It may be recalled that, for a non-compliance procedure to be set in motion, the existence of a dispute is not necessary. The procedure may be triggered also by the very Party experiencing compliance problems and this is one of the few features common to all non-compliance mechanisms. Furthermore, it may be noted that, along the same lines, a situation in which the conduct of a Party is at variance with the obligations set forth in the relevant instrument - irrespective of the use of the terms "breach", "violation", or "non-compliance" to describe this situation - is not required for the compliance mechanism to be set in motion; nor is a finding to this effect necessary for the consequences flowing from the procedure to be deployed. Evidence shows that a potential or future violation may suffice for addressing recommendations to a Party concerned.

${ }^{25}$ See T. Marauhn, "Towards a Procedural Law of Compliance Control in International Environmental Relations", ZaöRV, 56 (1996) 696-731, at 731; V. Röben, "Institutional Developments under Modern International Environmental Agreements”, Max Planck YB UN L., 4 (2000) 363-443, at 412; G. Handl, “Compliance Control Mechanisms and International Environmental Obligations", Tul. J. Int'l \& Comp. L., 5 (1997), 29-49, at 45; Voïnov Kohler, supra n. 3, at 115-116; V. Koester, "The Convention on Access to Information, Public Participation in Decision-Making and Access to Justice in Environmental Matters (Aarhus Convention)", in Ulfstein, Marauhn, and Zimmermann (eds.), supra n. 8, 179-217, at 204.

${ }^{26}$ Boisson de Chazournes and Mbengue, supra n. 3. 
Moreover, the procedure through which the possible existence of a situation of actual or potential non-compliance is determined is very different from the procedure before a court. Usually, only the Party concerned is entitled to take part in a compliance procedure as a guarantee of the fairness of the latter. In some cases similar participatory entitlements are recognised also to the Party (or possibly the non-State actor) that has initiated the procedure. ${ }^{27}$ The rationale for this, however, seems to be that of giving to the compliance body a more objective picture of the situation, enabling it to discharge more efficiently its tasks. In other words, the interest pursued by the recognition of participatory entitlements to the "complaining" Party or actor is considered to coincide with the general interest of having an efficient mechanism, rather than with the individual interests of the Party, or actor, involved.

This may be confirmed, by way of example, by observing the procedure before the Compliance Committee of the Aarhus Convention. In effect there is no direct confrontation between the parties involved, even when they present their arguments in front of the Committee. A further element relates to the flexibility of the procedure itself, as opposed to the rigid procedural rules of judicial proceedings. Such procedural flexibility is sometimes explicitly stated in the legal instruments instituting noncompliance mechanisms and may be confirmed by the prevailing practice. Again, the way in which the Compliance Committee of the Aarhus Convention works in practice sheds some light on the issue. To that end, one may refer to the examination of "admissibility requirements" for communications from the public, which is much less rigorous than the one under the procedure governing committees established under UN human rights treaties, not to mention that of the European Court of Human Rights. It is noteworthy that the same Committee has repeatedly stated that the scope of its review is not confined by that of the submission or communication at hand.

Finally, even when an actual situation has been determined to be one of non-compliance, it has been consistently held that the consequences of such finding are not those of State responsibility, with consequent remedial action, but those practically useful to engage in a process finally leading to full compliance.

These considerations emphasise how non-compliance procedures operate on a plan that is radically different from that of traditional inter-State claims of State responsibility, possibly through dispute settlement. The classical bilateral structure of the latter is lacking in the procedures under review. Furthermore, the expected outcomes of non-compliance mechanisms are considerably different from those of traditional disputes between States. A different dynamic seems to prevail in the context of noncompliance procedures, one in which a body representing a collective interest interacts with the subjects of regulatory measures. This dynamic concerns a State Party and a collective body acting in the common interest and takes place within the normative and institutional regime established by the relevant treaty. ${ }^{28}$ Its aim is to monitor, assess and facilitate compliance in a pragmatic and goal oriented manner. As

27 See M. Montini, "Procedural Guarantees in Non-Compliance Mechanisms", supra 389-405, at 395-396.

${ }_{28}$ See G. Ulfstein, "Dispute Resolution, Compliance Control and Enforcement in International Environmental Law", in Ulfstein, Marauhn, and Zimmermann (eds.), supra n. 8, 115-133, at 132 ("non-compliance procedures of MEAs are in fact very different [from dispute settlement procedures] by releasing the disputing parties from pursuing violations of MEAs on their own and entrusting it to the MEA institutions"). 
it has been argued previously, this does not mean that non-compliance procedures are not "legal" procedures, nor that general international law has no role to play, as States sometimes hint. The procedure itself is not only created and regulated by legal rules of different sources, such as treaty law and COP/MOP decisions, plus in some cases the procedural regulatory powers of the compliance body itself: what is more important is that the core of the functioning, as well as the task of non-compliance procedures, is precisely objective factual and legal assessment. In its turn, such assessment can only be based on the interpretation of the rules of international law, an exercise governed by general international law and that cannot take place, to use the wellknown words of the WTO Appellate Body, in "clinical isolation" from other rules of international law. ${ }^{29}$ Moreover, non-compliance mechanisms not only provide for assistance and facilitative measures, but also for stronger measures aimed at sanctioning refusal to cooperate or wilful and continuous non-compliance.

All in all, non-compliance procedures may be considered to be "located within a wider category of non-confrontational avoidance procedures" ${ }^{\prime 30}$ and defined as administrative procedure ${ }^{31}$ within regimes created by MEAs.

${ }^{29}$ US-Gasoline, doc. WT/DS2/AB/R, at 17, DSR 1996:I, 3 at 16. This view was shared, as noted above, by the Espoo Convention Implementation Committee. A similar position was taken by the Aarhus Convention Compliance Committee, see Pitea, supra n. 18 at 239.

${ }^{30}$ M. Fitzmaurice, "International Protection of the Environment", in RdC, 293 (2001) 9-488, at 348. See also G. Hand1, "Controlling Implementation of and Compliance with International Environmental Commitments: The Rocky Road from Rio", Colo. J. Envt'l L. \& Pol'y, 5 (1994) 305-331, at 329 (stating that compliance procedures may be characterised as a system of multilateral assistance for dispute avoidance, at least when a real dispute cannot be singled out).

${ }^{31}$ See K. Raustiala, "Compliance and Effectiveness in International Regulatory Cooperation", Case Western Reserve Journal of International Law, 32 (2000) 387-440, at 419. The use of this term does not imply total adhesions to recent theories on the emergence of "global administrative law" as a distinct international legal order from public international law. For the debate on this concept, see the special number on "The Emergence of Global Administrative Law", in Law and Contemporary Problems, 68 (2005), the Symposium in Eur. J. Int'l L., 17 (2006) 1-278. 